\title{
Study on Farmers' Selling Price, Average Annual Income and the Increase of Hubei Rape Planting Area: An Evidence from Huanggang, Jingzhou and Jingmen Cities
}

\author{
Chen Yunfei ${ }^{1,2}$, Feng Zhongchao ${ }^{1,}$, \\ ${ }^{1}$ Economics \& Management College, Huazhong Agricultural University, Wuhan, China \\ ${ }^{2}$ Economics \& Management College, Wuhan Polytechnic University, Wuhan, China \\ Email address: \\ hcl315@sina.com (Chen Yunfei), fengzhch@163.com (Feng Zhongchao) \\ ${ }^{*}$ Corresponding author
}

\section{To cite this article:}

Chen Yunfei, Feng Zhongchao. Study on Farmers' Selling Price, Average Annual Income and the Increase of Hubei Rape Planting Area: An Evidence from Huanggang, Jingzhou and Jingmen Cities. Engineering and Applied Sciences. Vol. 3, No. 2, 2018, pp. 40-46. doi: $10.11648 /$ j.eas.20180302.11

Received: May 26, 2018; Accepted: June 12, 2018; Published: July 5, 2018

\begin{abstract}
For purpose of the profit maximization, taking Huanggang, Jingzhou and Jingmen as the 3 representative cities (or states or districts) of the main rape planting areas in Hubei and using their time-arranged (1990-2014) data of rape planting areas, farmers' selling price of rapeseed and the average annual income, this paper try to give an empirical analysis on the supply response of rape planting area to such 3 factors of the year one phase lagging with Nerlove model. The research makes it clear that, firstly, there is large impact of the original production scale or habits on future rape planting area in Hubei. Secondly, the feature of rape planting in Hubei lies in rigidity of self demand totally and there is little impact of famers' selling price on rape planting area in Hubei in long-run. Thirdly, there is large impact of farmers' average annual income on rape planting area in Hubei in long-run. At the same time, the impact on rape planting differs among the 3 cities (or states or districts) especially for Jingzhou City (or the 2nd representative city) of its "inferior goods" tendency in economics.
\end{abstract}

Keywords: Rapeseed, Planting Area, Farmers' Selling Price, Farmers' Average Annual Income, Nerlove Model

\section{Introduction}

The safety of edible oilseeds supply in China is facing serious threats. According to statistics, China's annual output of edible oilseeds is about 56 million tons while the consumption has exceeded 100 million tons. Among them, more than $80 \%$ of the soybean, the most consumed one in China, are imported. The amount imported in 2017 even exceeded 95 million tons.

To increase the supply of edible oilseeds, the rape cultivation bears a heavy responsibility. Not only rapeseed has been the largest output edible oilseeds in China, but also there is great growth potential in it. According to statistics, at present, only the rape cultivated area of the main rapeseed production districts in the Yangtze River basin could be increased more than 3 million $\mathrm{hm}^{2}$ whose theoretical output is over 6 million tons per year. At the same time, in recent years, amounts of scientific and technological innovations in rape cultivation in China have made it possible to support the heavy burden of increasing output.

Under this situation, it is a big opportunities for Hubei in rape planting because it is not only the most important rape planting province but also the key rape industry developing area in China. According to statistics, from 1996 to 2015, a number of indicators such as the total rapeseed yield, which accounts for about $1 / 6$ of the nation and $1 / 22$ of the word, and high-quality-rapeseed rate, with the popularity of "double low" (that is low erucic acid and low glucosinolate) rapeseed reaching nearly $100 \%$ and thus the largest "double low" rapeseed production base in China particularly, in Hubei have been ranked first in the country for 20 years. In 2011, Hubei also proposed to build a "100 billion Yuan" project for rape industry in this province.

However, the current situation of rape planting in Hubei is not optimistic. According to the statistics, in 2016, the total production of rapeseed in Hubei was 2.416 million tons with 
a reduction of 136 thousand tons over the past year and decreasing by $5.3 \%$, which made Hubei lost the first status of the country in total output 20 years later in rapeseed production.

As we know, the scale of rape planting is the most important impact factor in of rapeseed yield [1]. The decrease of total output of rapeseed in Hubei in 2016 is closely related to the decline in the planting scale. In fact, Hubei province had lost its first place in planting scale in 2011. According to statistics, the scale of rape planting in Hubei was 1,135,000 $\mathrm{hm}^{2}$ in that year, reducing $97,000 \mathrm{hm}^{2}$ year-on-years or declined by $7.9 \%$. Therefore, it is of great practical significance to explore the impact factors, influencing effects and corresponding policy implications of rape planting scale in Hubei.

\section{Literatures' Review and Basic Theories}

In terms of the impact factors in scale of rape planting, there are many studies at home and abroad which differ greatly among scholars. Raducan (2012) thinks that the planting scale is affected by its planting pattern [2]. Arthur Yung (1770) thinks that the scale of planting should be determined by maximizing profits. Massoud (2000) considers that the factors affecting planting scale include the price of agricultural products, the agricultural industry and the efficiency of agriculture [3]. Guo Xibao and Feng Lingling (2015) think that the main influencing factors of planting scales are the level of economic development, technological progress, manufacturing industry - agricultural wage ratio and labor - capital price ratio [4]. Guo Qinghai (2014) believes that the influencing factors of planting scale are operating cost or income [5]. Fu Tingdong (2017) thinks that the large scale, mechanization and multipurpose are effective ways to increase the benefit of rape planting and thus promote the scale of it. Li Lianjun (2017) considers that the factors affecting the planting scale are land scale, land circulation and households' degree of education [6]. Li Ran and Li Gucheng, etc. (2015) think that the rape planting scale is closely related to the efficiency of agricultural production [7]. Bao Xiaoli and Wang Xiao Wei, etc. (2016) believe that the main affecting factors of the planting scale are the cost-benefit of competitive crops, the one-year lagging rape planting area and per unit yield [8]. Chen Yunfei and Feng Zhongchao (2018) think that the potential rapeseed production in China mainly depends on the utilization of winter fallow fields in the main winter-rape production provinces in Yangtze basin including Hubei [9].

At the same time, some scholars had studied the effects of the rape planting scale influencing factors using theoretical or empirical methods. Among them, Li Ran and Li Gucheng, etc. (2015) had studied the appropriate operation scale of rape planting in different provinces using the economic efficiency. Li QinZhi and Wang Houjun (2013) took an empirical study of the impacts of wheat planting area, soybean importing quantity, production value and cost per unit on the rape planting area [10]. Huang Jia (2006) had studied the supply response of rape planting area in China to the farmers' selling price on the lagging phase of rapeseed, the farmers' selling price of alternative crop wheat and the planting area of rape using the Nerlove model based on the time series data in 1981-2003 [11].

The research literatures of scholars have very important theoretical or practical values for analyzing the scale of rape planting and its influencing factors in Hubei, especially the study of the supply response of rape planting scale in China from Huang Jia (2006) using the Nerlove model. Because as a response of the scale (or output) to the price or other impact factors, the supply response' estimation has not dynamic analysis significance until Nerlove's research although it had been researched in western countries earlier [12]. Therefore, the Nerlove model had been applied more and more extensively and deeply in modern domestic and foreign research on supply problems of agricultural products and so scholars had used this model to study the supply response of a variety of agricultural products, such as Kenya coffee (Maitha, 1970); Garner cotton (Seini, 1985); Ireland's six main agricultural products from 19th to 20th centuries (Grada C, 1975) [13];Chinese table poultry (Xin Xiangfei, Wang Zuli, etc., 2017) [14]; Chinese vegetable (Li Guofei and Xu Guangcai, 2016) [15]; large scale rural land circulation to grain yield (Niu Xin, Wu Yueting, etc., 2018) [16] and so on.

Unfortunately, Huang Jia (2006), in the study of the supply response of Chinese rape planting scale using the Nerlove model, put such 3 provinces of Henan, Hubei and Hunan in one group according to the south central region. As a fact, Henan is an important winter wheat producing province in China while Hubei and Hunan are important winter rape producing provinces in China. Moreover, even in the same province, there are some differences in the response degree of the supply of rape planting scale due to the differences in the natural conditions, economic development and the market construction levels among cities (or states or districts).

At the same time, Huang Jia (2006) did not give the theoretical basis for the selected influence variables when using the Nerlove model to study the response degree of the Chinese rape planting scale to its influence variables. In fact, the differences between scholars' research methods and the conclusions of their studies come from this. In this paper, according to the economic principles, under the premise of the hypothesis of a farmer household as an economic man, the planting scale is influenced by many factors such as expectation, substitutes, and technological changes and so on, but the main purpose is to maximize the profits. That is, $\pi_{\max }$ $=(\mathrm{P}-\mathrm{AC}) \mathrm{AA} * \mathrm{PP}$ (where $\mathrm{P}$ represents selling price, $\mathrm{AC}$ means average cost, AA indicates planting scale, and PP represents unit yield). Therefore, the growth of rapeseed should be mainly influenced by variables such as household income, selling price of rural goods, average cost and yield per unit area instead of other influencing variables such as planting patterns land transfer system and production efficiency, etc.

The literatures' review and theoretical analysis show that the Nerlove model is an effective tool for dynamic analysis 
of rape planting scale and its influencing variables in Hubei. At the same time, considering following conditions that Hubei is facing the similar expectation and technological changes of rape planting; there are plenty of winter fallow fields in Hubei; in the main producing area of rapeseed, rapeseed production is basically not contending with wheat, which is a possible competitive crop in winter; the yield and average cost of rape planting in Hubei are also partly reflected in technological changes and selling price. Therefore, Nerlove model is used by the dynamic analysis in the growth of rape planting scale in Hubei. As for the selection of influence variables, in addition to the influence of planting habits on the planting scale of rape, two other influence variables as farmers' selling price and average annual net income of local farmers with one-year lagging are selected to explore the supply response degree and policy implications of rape planting scale in Hubei.

\section{Model Specification and Parameter Estimation}

\subsection{Model Specification}

The direct estimation using Nerlove model may lead to the assumption that the result violates the normal distribution of residuals. In order to ensure that the residual terms are normally distributed, in this paper, each variable is processed by logarithmic process. In addition, the long-term elasticity of supply can be obtained directly from the coefficients in logarithmic form.

At the same time, considering that the estimation of OLS may have sequence autocorrelation or multicollinearity and thus the estimation results may not linear unbiased estimators. In this paper, the lagging variables and the GLS are used in the estimation.

Based on the analysis above, the supply response model of rape planting scale in Hubei is as follow:

$$
\ln \mathrm{AA}_{\mathrm{it}}=\mathrm{a}_{\mathrm{i} 0}+\mathrm{b}_{\mathrm{i} 1} \ln \mathrm{AA}_{\mathrm{it}-1}+\mathrm{b}_{\mathrm{i} 2} \operatorname{lnRP_{\mathrm {it}-1}}+\mathrm{b}_{\mathrm{i} 3} \ln \mathrm{PI}_{\mathrm{it}-1}+\mu_{\mathrm{it}}
$$

Among (1), $\mathrm{AA}_{\mathrm{it}}$ represents the rape planting scale in Hubei in current period. RP shows the farmers' selling price of rapeseed in Hubei; PI indicates the farmers' average annual net income; $\mathrm{i}$ represents the selected Hubei rape planting representative group; $t$ represents the year. $a$ and $b$ indicate the undetermined parameters; $\mu$ indicates the random error.

In the results of the model, the expected value of rape planting scale, farmers' selling price and average net income of local farmers are positive.

\subsection{Variable Description and Data's Sources}

In this paper, the scale of rape cultivation in Hubei is used as output variable (AA), excluding the area of loss caused by natural disasters, with $\mathrm{hm}^{2}$ as a unit.

The selected influence variables in this paper include: the farmers' average annual net income (PI), which is the income of the statistical yearbook caliber statistics, in unit of Yuan; the farmers' selling price of rapeseed (RP), which is the actual selling price of rape planted by farmers, Yuan is its unit.

Since 2014, the average annual net income index of local farmers has been adjusted to be the average annual disposable income of local farmers, there is no comparability between them. Therefore, except for rapeseed planting scale data is used in 2014, other variables sample data used are in 1990-2013.

Hubei is a province located in the central part of China that there are certain differences in natural conditions, economic development and market construction levels in the eastern, central and western regions in it. There must be some differences in the scale of rape planting and the degree of response to supply. Reconsidering the duration of the longitudinal data in1990-2014 is not very long and the accessibility of data across administrative regions is very high, in this paper, the dynamic analysis of the growth of rape planting scale in Hubei will be done based on the administrative divisions. In 2015, 10 cities (or states or districts) with the largest rape planting area in Hubei were Jingzhou, Huanggang, Jingmen, Yichang, Xiaogan, Xiangyang, Wuhan, Xiantao, Qianjiang and Tianmen. According to the Q clustering, the main cities (or states or districts) of rape cultivation in Hubei (main can be divided into four groups [17]. The 1-3 groups are the 3 cities of Huanggang, Jingzhou and Jingmen, and the other 7 cities (or states or districts) are the fourth group. In fact, the 1-3 groups are also the representative areas of rape planting in the eastern, central and western Hubei and the core areas of the main regions of Hubei rapeseed production in southeast Hubei, Jianghan Plain and northern Hubei. So the 3 groups were selected as the representative groups to study the supply response of rape planting scale in Hubei. Among the 3 groups, the highest average annual net income of farmers is in Jingmen city and the lowest ones is in Huanggang city. The largest and the average rape planting scale group is Jingzhou city, and the smallest one is Huanggang city. There have similar farmers' selling price of rapeseed among groups.

All data in the study are derived from the selected cities' Yearbooks, the Hubei Yearbooks, the Hubei Statistical Yearbooks and the Compilation of the National Agricultural Product Cost and Income Data. For the individual missing data in the groups or the changes of data from the adjustment of administrative division, this paper takes the corresponding data of the whole province to adjust it firstly, and then adjusts it according to the corresponding national data.

\subsection{Model Parameter Estimation}

\subsubsection{Cointegration Test}

First of all, the unit root test was carried out on 3 variables including rape planting scale, farmers' selling price of rapeseed and average annual net income in Hubei in 1990-2013. The results are shown in Table 1. 
Table 1. ADF test results (lnA $\left.A_{i t-1}, \ln R P_{i t-1}, \ln P I_{i t-1}\right)$ of rape planting in Hubei province.

\begin{tabular}{|c|c|c|c|c|c|}
\hline groups & variable & Test $(\mathrm{C}, \mathrm{T}, \mathrm{K})$ & ADF test & $5 \%$ critical value & conclusion \\
\hline \multirow{6}{*}{1} & $\ln \mathrm{AA}_{1 \mathrm{t}-1}$ & $(\mathrm{~N}, \mathrm{~N}, 0)$ & 1.83 & -1.96 & notstable \\
\hline & $\Delta \ln \mathrm{AA}_{1 \mathrm{t}-1}$ & $(\mathrm{~N}, \mathrm{~N}, 0)$ & -4.22 & -1.96 & stable \\
\hline & $\ln R P_{1 t-1}$ & $(\mathrm{C}, \mathrm{N}, 1)$ & -1.56 & -3.00 & notstable \\
\hline & $\Delta \ln R P_{1 t-1}$ & $(\mathrm{~N}, \mathrm{~N}, 0)$ & -4.30 & -1.96 & stable \\
\hline & $\operatorname{lnPI} I_{1 t-1}$ & $(\mathrm{C}, \mathrm{N}, 1)$ & -1.89 & -3.00 & notstable \\
\hline & $\Delta \ln P I_{1 t-1}$ & $(\mathrm{C}, \mathrm{N}, 0)$ & -3.65 & -3.00 & stable \\
\hline \multirow{6}{*}{2} & $\ln \mathrm{AA}_{2 \mathrm{t}-1}$ & $(\mathrm{~N}, \mathrm{~N}, 0)$ & 1.80 & -1.96 & notstable \\
\hline & $\Delta \ln \mathrm{AA}_{2 \mathrm{t}-1}$ & $(\mathrm{~N}, \mathrm{~N}, 0)$ & -3.85 & -1.96 & stable \\
\hline & $\ln R P_{2 t-1}$ & $(\mathrm{C}, \mathrm{N}, 1)$ & -1.14 & -3.00 & notstable \\
\hline & $\Delta \ln R P_{2 t-1}$ & $(\mathrm{~N}, \mathrm{~N}, 0)$ & -4.01 & -1.96 & stable \\
\hline & $\ln \mathrm{PI}_{1 \mathrm{t}-1}$ & $(\mathrm{~N}, \mathrm{~N}, 0)$ & 5.43 & -1.96 & notstable \\
\hline & $\Delta \ln P I_{1 t-1}$ & $(\mathrm{C}, \mathrm{N}, 0)$ & -3.97 & -3.00 & stable \\
\hline \multirow{6}{*}{3} & $\ln \mathrm{AA}_{3 \mathrm{t}-1}$ & $(\mathrm{~N}, \mathrm{~N}, 0)$ & 0.98 & -1.96 & notstable \\
\hline & $\Delta \ln \mathrm{AA}_{2 \mathrm{t}-1}$ & $(\mathrm{~N}, \mathrm{~N}, 0)$ & -4.43 & -1.96 & stable \\
\hline & $\operatorname{lnRP} P_{3 t-1}$ & $(\mathrm{~N}, \mathrm{~N}, 0)$ & 1.04 & -1.96 & notstable \\
\hline & $\Delta \operatorname{lnR} P_{3 t-1}$ & $(\mathrm{~N}, \mathrm{~N}, 0)$ & -4.56 & -1.96 & stable \\
\hline & $\operatorname{lnPI} I_{1 t-1}$ & $(\mathrm{~N}, \mathrm{~N}, 0)$ & 2.80 & -1.96 & notstable \\
\hline & $\Delta \ln \mathrm{PI}_{1 t-1}$ & $(\mathrm{~N}, \mathrm{~N}, 0)$ & -2.11 & -1.96 & stable \\
\hline
\end{tabular}

Notes: the test results in this table are calculated by Eviews7.2. $\Delta$ represents difference operator. $\mathrm{N}$ represents $\mathrm{C}$ or $\mathrm{T}$ is not included. $\mathrm{C}, \mathrm{T}, \mathrm{K}$ represent the intercept item, time trend and delay order respectively in $(\mathrm{C}, \mathrm{T}, \mathrm{K})$,

The test results in Table 1 show that the logarithm of all variables is first-order and single integer, indicating that all variables satisfy the necessary conditions for cointegration. Further, JJ test is used to perform the cointegration test on $\ln \mathrm{AA}_{\mathrm{it}-1}, \operatorname{lnRP} \mathrm{P}_{\mathrm{it}-1}$ and $\operatorname{lnP} \mathrm{I}_{\mathrm{it}-1}$, and the results are shown in Table 2.
It can be seen from Table 2 that there is a cointegration relationship or a long-term equilibrium relationship among variables in each group, so there will be no spurious regression. The long-term resilience of rape planting area is calculated next, and the results are shown in Table 3.

Table 2. JJ test results $\left(\ln A A_{i t-1}, \ln R P_{i t-1}, \ln P I_{i t-1}\right)$ of rape planting in Hubei province.

\begin{tabular}{lllllll}
\hline groups & Characteristic value & $\mathbf{H}_{\mathbf{0}}$ & $\mathbf{H}_{\mathbf{1}}$ & Like hood & $\mathbf{5 \%}$ critical value & conclusion \\
\hline & 0.1441 & $\mathrm{R}=0$ & $\mathrm{R}=1$ & 3.4244 & 3.84 & notrefused \\
& 0.1911 & $\mathrm{R}=1$ & $\mathrm{R}=2$ & 7.5798 & 15.49 & notrefused \\
& 0.7195 & $\mathrm{R}=2$ & $\mathrm{R}=3$ & 44.2266 & 29.80 & efusedr \\
2 & 0.2262 & $\mathrm{R}=0$ & $\mathrm{R}=1$ & 5.6426 & 3.84 & refused \\
& 0.2452 & $\mathrm{R}=1$ & $\mathrm{R}=2$ & 7.3947 & 15.49 & notrefused \\
& 0.6246 & $\mathrm{R}=2$ & $\mathrm{R}=3$ & 32.1494 & 29.80 & refused \\
3 & 0.1679 & $\mathrm{R}=0$ & $\mathrm{R}=1$ & 4.0440 & 3.84 & refused \\
& 0.1759 & $\mathrm{R}=1$ & $\mathrm{R}=2$ & 5.4131 & 15.49 & notrefused \\
& 0.7648 & $\mathrm{R}=2$ & $\mathrm{R}=3$ & 44.2896 & 29.80 & refused \\
\hline
\end{tabular}

Notes: R represents the number of cointegrating vectors.

Table 3. long-run response elasticity of rape planting scale in Hubei province.

\begin{tabular}{lll}
\hline groups & farmers' selling price & farmers' average annual net income \\
\hline 1 & 0.185 & 6.687 \\
2 & 0.413 & -15.118 \\
3 & 0.069 & 11.790 \\
\hline
\end{tabular}

\subsubsection{Regression Analysis}

Using GLS, the estimated results are as follows $(* * *, * *, *$ indicate significance at the $1 \%, 5 \%$, and $10 \%$ levels, respectively):

$$
\begin{array}{r}
\ln \mathrm{AA}_{1 \mathrm{t}}=0.9200+0.3722 \ln \mathrm{AA}_{1 \mathrm{t}-1} \\
(2.3357)^{* *}(1.9922)^{*} \\
+0.0711 \ln \mathrm{lP}_{1 \mathrm{t}-1}+0.2387 \ln \mathrm{II}_{1 \mathrm{t}-1} \\
(0.7419) \quad(2.0981)^{* *}
\end{array}
$$

$$
\ln \mathrm{AA}_{2 \mathrm{t}}=0.5064+0.7611 \ln \mathrm{AA}_{2 \mathrm{t}-1}
$$

$$
(1.0187) \quad(4.7862)^{* * *}
$$$$
+0.1692 \operatorname{lnRP}{ }_{2 \mathrm{t}-1}-0.0608 \ln P \mathrm{I}_{2 \mathrm{t}-1}
$$

$$
\text { (104.67) (-0.0585) }
$$

$\ln \mathrm{AA}_{3 \mathrm{t}}=0.9285+0.5734 \ln \mathrm{AA}_{3 \mathrm{t}-1}$

$$
(1.4787) \quad(2.8315)^{* *}
$$

$+0.0090 \operatorname{lnRP} P_{3 \mathrm{t}-1}+0.1235 \ln \mathrm{PI}_{3 \mathrm{t}-1}$

$$
(0.0556) \quad(1.0111)
$$


In (2)-(4), the values in the following parentheses in the function are $t$ test values. In the same time, in (2) or group1, $\mathrm{F}=114.9115, \mathrm{R}^{2}=0.9452$, adjusted $\mathrm{R}^{2}=0.9369$; in (3) or group2, $F=82.0064, R^{2}=0.9248$, adjusted $R^{2}=0.9135$; in (4) or group3, $\mathrm{F}=28.1445, \mathrm{R}^{2}=0.8085$, adjusted $\mathrm{R}^{2}=-0.7798$.

\subsection{Results Analysis}

It can be seen from the estimated results that there are certain differences in the degree of supply response among the 3 representative groups of rape planting in Hubei, which is not entirely consistent with the expectations. Among them, the variables of planting area and the farmers' selling price of rapeseed in the first lag phase are all positive which is consistent with the expectations. The farmers' average annual net income in the first and third group is positive while it is negative in the second group, which is not consistent with the expectations. On the $\mathrm{R}^{2}$ value, the 3 groups are all above 0.8 . Based on $t$ statistics, various degrees of statistical significances are observed. The intercept of the first group is $5 \%$ significant. The planting area of the 3 groups is $10 \%, 1 \%$ and 5\% significant respectively. The local farmers' average annual net income of the first lag phase in the first group is significant at $5 \%$ level.

The estimated results show that the model is well-fitted, especially the first group of Huanggang city. In this group, except for farmers' selling price of rapeseed, other variables are all significant. Therefore, the above estimation results can better explain some factors of the changes of rape planting scale in Hubei since 1990. Among them, all the variables in the specific models of the first lag phase are positive, not only the coefficients are larger, but also they are significant. It shows that the original planting scale or habit of rape planting in Hubei has strong influence on the future rape planting, especially in Jingzhou and Jingmen cities. In the 3 groups of specific models, the variables in the first phase lagged of farmers' selling price are all positive, but they are not significant, and the coefficients of the first, the third groups are very small which means that although the farmers' selling price of rapeseed has positive effect on rape planting in Hubei, it shows a character of rigidity in general, especially in Huanggang and Jingmen cities. The average net annual income of the local farmers in the lagged period is positive or negative in the specific models of each group. Among them, it is positive in Huanggang city, which is significant too, and Jingmen city, it is negative in Jingzhou city but the coefficient is very small. All these shows that the farmers' average annual net income in different regions in Hubei has different influences on rape planting. Among them, the second group of Jingzhou city shows the possible tendency of "inferior goods" in rape planting. That is, the increase of farmers' average annual net income of may increase the opportunity cost of rape planting and thus affect the expansion of rape planting scale.

In each group, the long-term response elasticity of rape planting scale to farmers' selling price of rapeseed is less than 1 especially in the first group and the third group, of which the elasticity is 0.069 in the third group only. All these indicate the rigidity of rape planting. At the same time and reflect that in the long run, the changes of farmers' selling price of rapeseed will affect the changes of the rape planting scale in Hubei. But these changes are generally stable except for the relative larger changes in Jingzhou city.

The elasticity of rape planting scale to the average annual net income of the local farmers in 3 groups is all more than 1 , of which the second and the third group are larger with more than 10 and the first group also exceeds 6. All these show that in the long run, the changes of rape planting scale vary greatly with the average annual net income of local farmers, especially in Jingzhou and Jingmen cities.

In conclusion, from the above analysis, we can conclude that, firstly, the estimated results of Hubei rape planting scale model have strong explanatory power; that the significance of the rape planting scale of lagging and the long-term response farmers' selling price of rapeseed are less elastic indicates that the main rigid self demand feature of rape cultivation in Hubei at present; at the same time, that the impact of selling price variable of rapeseed is not significant indicates that whether there are other factors need to be further explored. Secondly, Hubei is located in central China, there are certain differences in the natural conditions and economic development of the land and climate in the East, middle and west, there are certain differences in the influence factors and long-term elasticity of rape planting, therefore in the second group, the rape planting scale decreased with the increase of average annual net income of local farmers in Jingzhou city, while the rape planting scale increased with the average annual net income of local farmers in Huanggang city, which also shows the significance, and Jingmen city. Thirdly, from the scope of long term elasticity, the farmers' selling price of rapeseed has little impact on the scale of rape planting; the average annual net income of local farmers has great influences on the changes of the rape planting scale.

\section{Conclusions}

From the result analysis, such conclusions could be arrived that, firstly, there is large impact of the original production scale or habits on future rape planting area in Hubei. Secondly, the feature of rape planting in Hubei lies in rigidity of self demand totally and there is little impact of famers' selling price on rape planting area in Hubei in long-run. Thirdly, there is large impact of farmers' average annual income on rape planting area in Hubei in long-run. At the same time, the impact on rape planting differs among the 3 cities (or states or districts) especially for Jingzhou City (or the 2nd representative city) of its "inferior goods" tendency in economics.

\section{Policy Implications}

\subsection{Stable the Rape Planting Area}

Although the scale of rape cultivation in Hubei exhibits the feather of rigidity of self demand totally, it was greatly 
influenced by the average annual net income of local farmers. Therefore, in order to stabilize and even expand the scale of rape planting in Hubei, it is necessary to take measures to stabilize the existing planting area and habits by strengthening the advantages of rapeseed's products and the multipurpose use of rape planting. In particular, the second group of Jingzhou city and the third group of Jingmen city are not only the area with strong influence in original planting scale or habit of the future rape planting, but also the area which is most affected by the average annual net income of local farmers while Jingzhou city is the largest rape planting area in Hubei and Jingmen city is the key area for rape production in Hubei which always enjoys the reputation of "Chinese rape depends on Hubei and the rape of Hubei depends on Jingmen".

\subsection{Stabilizing the Farmers' Selling Price Expectation of Rapeseed}

Although the variable of one-phase lagging farmers' selling price of rapeseed has little influence on the rape planting scale. However, it still has some influences in the short run even may change farmers' rape planting habits for rural households. According to the analysis, that the rape planting in Hubei decreased by about $7.9 \%$ year on year in 2016 is considered to be closely related with the policy of canceling the temporary purchase and storage of rapeseed in 2015 in short term. In the year, under the influence of policy adjustment, the farmers' selling price of rapeseed dropped by about $40 \%$ compared with the same period last year. Of course, the farmers' selling price of rapeseed has increased by about $30 \%$ in the late years due to the influence of domestic and foreign markets. Therefore, Hubei should takes measures to stabilize selling farmers' price expectation of rapeseed and clarify the rigid self requirement characteristics of rape planting to make sure that the farmers' selling price of rapeseed will not drop significantly in the long run. At the same time, it should be paid attention to the second group of Jingzhou city because the elasticity of rape planting scale in Jingzhou city is relatively larger than that of the farmers' selling price of rapeseed in the estimation model while Jingzhou city is located in Jianghan Plain which is suit for many crops to plant.

\subsection{Strengthen the Countermeasures Research of Rape Planting with the Farmers' Average Annual Net Income}

The report of 18th CPC national congress pointed out that many possible measures will be done to increase farmers' income because the achievement of development of the country should be shared by the people. However, the rape planted in winter in Hubei has a long span of time and the opportunity cost for farmers in rape planting will also increase with the increasing of the farmers' average annual net income. All these may affect the enthusiasm of farmers to grow rapeseed. Hubei should take some measures to strengthen the research on the scale of rape planting with the increasing of farmers' income and enhance farmers' ability to obtain opportunity cost for rape planting.

The income of rape planting is closely related to the scale of planting [18]. In the 3 groups, that the first group of rural households in Huanggang city has the smallest planting scale and the lowest farmers' average annual net income may be related to this. So the Central No.1 documents in recent years had made it clear that China will build a new agricultural operation system and develop various forms of moderate scale operation. According to statistics, there are still almost $3 \times 10^{5} \mathrm{hm}^{2}$ of "Three Kinds of Winter Fields" and showing a growth trend in Hubei. It is easy to achieve a moderate scale of operation. Hubei may realize the proper scale operation of rape production by encouraging short-term or long-term land circulation to increase the revenue of rape planting and the scale of rape planting.

\subsection{Strengthen the Influence Research on the Other Factors on Rape Planting Scale}

Based on the principles of economics, on the premise of the hypothesis of the rural households and aiming for profit maximization, that the effect of the variable of farmers' selling price of rapeseed is not significant in this article indicates that the growth of rapeseed planting scale in Hubei may be affected by other variables beyond the purpose of maximizing the profit of rape planting. According to the scholars' research views, these variables include the competition with the crop wheat in some areas, the multiple uses (for oil, for honey, for flower, for vegetable) and the "five transformations" (large scale, light simplification, integration, mechanization, standardization) in rape planting. Hubei may take measures to further strengthen the studying in the effects of these variables on the planting scale of rape planting and take corresponding countermeasures.

\section{Acknowledgements}

This paper is supported by such 2 foundation items as China Agricultural Research System (CARS-13) and the National Social Science Foundation of China: Chain-transfer of Migrant workers and the admitted ways of cities (16BJY102).

\section{References}

[1] Liu X L. "Research on impact factors of Hubei rapeseed production based on factor analysis method". Rural Economics and Technology, vol. 12, pp. 15-17, 2015.

[2] Raducan, Corina. "Autumn rapeseed production under the influence of sowing density in the conditions of S. C. D. A. Lovrin in 2011". Research Journal of Agricultural Science, vol. 44, pp. 134-137, 2012.

[3] Massoud K. "Relative prices and the international comparison of real agriculture output and productivity". Journal of Peasant Studies, vol. 27, pp. 112-137, 2000.

[4] Guo X B, Feng LL. "A theoretical and empirical analysis on the deciding factors of farm size". China rural Economy, vol. 5, pp. 82-95, 2015. 
[5] Guo Q H. "The Measurement of Land Appropriate Operation Scale: Efficiency or Income?” Rural Economy Problems, vol. 7, pp. 4-10, 2014.

[6] Li L J. "Study on impact factors of willingness on rice appropriate scale operation in main grain districts - based on the survey of 428 housholds of 7 conuties in Jiangxi Provice". China Rural Resource and Division, vol. 12, pp. 130-137, 2017.

[7] Li R, Li Gucheng, Feng Zhongchao. "Research on the economic efficiency of rape production by different households - based on the data 6 provinces in Hubei, SiChuan, etc." Journal of Huazhong Agricultural University (for social sceice), vol. 1, pp. 14-22, 2015.

[8] Bao Y L, Wang X W, Dai J X. "An analysis on impact factors of scale changes in cotton planting in Xinjing". Shanxi Agricultural Science, vol. 41(22), pp. 1877-1881, 2016.

[9] Chen Y F, Feng Zhongchao. "Research on the appropriate land scale operation of rape production based on dual aims - an evidence from 342 households in Hubei province". Hubei Agricultural Science, vol. 6, pp. 4475-4478, 2018.

[10] Li Q Z, Wang H J. "An analysis on impact factors of rape planting in China. Rural Technology Economy, vol. 11, pp. 120-127, 2013.

[11] Huang J. "An empirical analysis on production changing and impact factors on Chinese rapeseed". Beijing: China Agricultural University, 2006, pp. 29.
[12] BEAN L. H. "The farmer's response to price". Journal of Farm Economics, vol. 11, pp. 368-385, 1929.

[13] Fan L J, Mu Y Y, Fu W G. "The supply response of different grain crops in China based on Nerlove model”. Agricultural Technological Economy, vol. 12, pp. 4-11, 2012.

[14] Xin X F, Wang Z L, Wang J M. "Research on the supply response on China table poultry-- based on Nerlove model and dynamic panel data by different provinces". Journal of Agricultural \& Forest Economy \& Mangement, vol. 1, pp. 120-126, 2017.

[15] Li G F, Xu G C, Gao Y A. "Research on vegetable supply response in China based on Nerlove model". Anhui Agricultural Science, vol. 18, pp. 235-237, 2016.

[16] Niu X, Wu Y T, Wu G C. "An Empirical analysis on the large scale rural land circulation to grain yield - an evidence from Shanghai suburbs". China Land Resource Technology Management, vol. 2, pp. 116-126, 2018.

[17] ChenY F, Zhang Y M. "An empirical analysis on the district competitiveness in Hubei rape production". Journal of Wuhan Polytechnic University, vol. 4, pp. 82-84, 2013.

[18] Xu Q, Yin R L, Zhang H. "Economies of scale, returns to scale and the problem of optimum-scale farm management: An empirical study based on grain production in China". Economy Research, vol. 3, pp. 61-64, 2011. 